\title{
LA MODERNIZACIÓN DE LA EDUCACIÓN SUPERIOR EN AGUASCALIENTES
}

SALVADOR CAMACHO SANDOVAL

Departamento de Educación/UAA

BonIfacio BARBA, Las universidades y tecnológicos de Aguascalientes, Universidad Autónoma de Aguascalientes/Instituto de Educación de Aguascalientes, Aguascalientes, 1998.

Wl libro estudia el origen y desarrollo de las instituciones de educación superior en Aguascalientes, excepto las normales -a las que ya dedicó otro estudio, junto con Margarita Zorrilla-. Su periodo de análisis abarca desde los años sesenta hasta el año de 1995. Desafortunadamente, el autor no pudo analizar la creación de la Comisión Estatal de Educación Superior, la reforma y conflictos en la Universidad Autónoma de Aguascalientes en 1997 y el establecimiento del Instituto Tecnológico de Monterrey, acontecimientos que lo hubieran dado ciertos matices a sus conclusiones.
El texto no es un recuento de fechas y sucesos, sino un análisis del desarrollo de las universidades y tecnológicos como un proceso socioinstitucional que va desde la elaboración de los proyectos y su puesta en marcha hasta la manera en que hacen frente, se incorporaron o resistieron a la política de modernización del gobierno de Carlos Salinas de Gortari.

El libro está bien estructurado y logra una coherencia tal que lleva a los lectores de la mano para decirnos cuáles fueron sus propósitos y preguntas iniciales, cuáles fueron sus herramientas metodológicas y técnicas, qué entiende por educación superior, qué elementos conceptuales y teóricos le ayudaron a fundamentar su estudio, cuál era el contexto nacional de la aparición de las instituciones de educación superior en el estado y cuál era el desarrollo socioeconómico de Aguascalientes, contextos que propiciaron el surgimiento y el tipo 
de desenvolvimiento que dichas instituciones tuvieron, para de esta manera abordar, ya en la tercera y más importante parte del libro, a todas y cada una de las universidades y tecnológicos de Aguascalientes.

En esa tercera parte están las aportaciones más originales de Bonifacio. Su aportación principal no está en la teoría, ni en el análisis de la educación en México, ni en la buena síntesis que hace sobre la realidad social, económica y política de Aguascalientes, sino en la manera profunda y consistente en que describe y analiza el origen, los proyectos, el desarrollo y los principales problemas de ocho instituciones: Universidad Autónoma de Aguascalientes, Instituto Tecnológico de Aguascalientes, Instituto Tecnológico Agropecuario $N^{\circ}$. 20, Centro Universitario Galilea, Universidad Bonaterra, Universidad Tecnológica de Aguascalientes, Universidad Cuauhtémoc y Centro Universitario de Aguascalientes.

En la cuarta y última parte del libro se funden de una manera armoniosa todos los capítulos anteriores. Además, para dar validez a sus conclusiones $y$, en general a todo su trabajo, no hubo necesidad de aplicar cientos de cuestionarios estructurados ni hacer operaciones estadísticas sofisticadas. $\mathrm{Y}$ es de resaltar este rasgo metodológico del trabajo, porque se dife- rencia de la tendencia cuantitativa de la investigación educativa que suele hacerse en la UAA. Obviamente no se puede decir que de un lado y otro se esté en lo correcto o incorrecto académicamente, sino que, más allá de las discusiones entre los cuantitativistas y cualitativistas, el autor hace una aportación de gran valía con su obra y abre una perspectiva amplia de investigación. Él mismo se encarga, al final de su libro, de hacer una lista de temas que se derivan de su estudio.

De la lectura del trabajo se desprenden diversos temas que propician la reflexión y el cuestionamiento. Por ejemplo, hay una parte que no queda muy clara: se trata del uso de la teoría. Esta inquietud se relaciona con la constante preocupación que tienen las personas que investigan y que enseñan a investigar. Desde la licenciatura se dice que para investigar hay que hacer primero un marco teórico, pero los investigadores en educación, y en particular los de Aguascalientes, en su mayoría, no son sociólogos, economistas, psicólogos, antropólogos o historiadores. Alguien, tal vez para consolar, dijo que esto era una ventaja, pues se hacía un uso crítico de las teorías y las usaban sin casarse de antemano con una de ellas. En parte esto es cierto, y el trabajo de Bonifacio Barba da muestra de cierto eclecticismo sano, digámoslo así. Pero también queda la duda 
sobre si este trabajo pudo haber llegado a las mismas conclusiones sin haber tenido esos capítulos iniciales de lo que podríamos llamar "marco teórico". De muchos trabajos y tesis existentes no cabe la menor duda: no pocos estudiosos pueden evitar la búsqueda tesonera y entretenida de "la o las teorías" para hacer sus instrumentos de recopilación y análisis de datos y llegar a concluir lo mismo.

En el libro, con todo, hay elementos teóricos que son usados de manera muy adecuada y que llaman la atención, por ejemplo, la manera como introduce algunas tesis de las teorías de la modernización. De este último vale la pena ocuparse.

La teoría de la modernización le ayudó al autor para hacer referencia, tanto al origen de las universidades europeas en el siglo XII como a las instituciones de educación superior en México después de la crisis política de los sesenta. Tal vez esta generalización sea un tanto forzada. En este mismo sentido, uno puede preguntarse: ¿En qué momento la sociedad mexicana dejó de ser tradicional para convertirse en moderna? ¿Las instituciones de educación superior en Aguascalientes respondieron a un proceso de modernización económica y social de México y Aguascalientes y no hubo algún rasgo tradicional en sus procesos? A pesar de lo impreciso de las fronteras entre lo tradicional y lo moderno, parece que el esquema bipolar es útil para el análisis e interpretación del trabajo, incluso puede hacerse más.

Richard Brown, un estudioso de los procesos de modernización en Estados Unidos, nos aclara que la dirección del proceso puede ir en sentido inverso, es decir hacia la tradicionalización, además de que puede haber elementos tradicionales y modernos coexistiendo en una misma sociedad, y uno diría en una misma institución educativa. Y si Barba caracteriza lo moderno para explicar los avances de la educación superior, también puede caracterizare el mundo tradicional para explicar la manera zigzagueante y a veces contradictorio del desarrollo de la educación superior en Aguascalientes.

La primera característica del mundo tradicional es la referencia constante al pasado y, en este sentido, la sociedad tradicional es gobernada por la igualdad del tiempo, pues, según Edward P. Thompson, no hay razón para creer que "el tiempo es oro". Su dinámica es cíclica y no lineal, de menos a más con perspectiva de futuro. En la vida familiar e institucional tradicional, la estabilidad es sobrevalorada y se prefieren las comunidades pequeñas y una comunicación "cara a cara", entendiendo que el localismo circunscribe también al pensamiento y a la conducta. En las instituciones tradicionales se mantie- 
ne el statu quo y la jerarquía, algunas veces controlada por autoridades paternalistas y carismáticas, la participación de las bases es mínima y hay resistencia al pluralismo, la secularización y la innovación. La personalidad tradicional es la del individuo que se adapta a los valores y normas que han estado arraigados por muchos años en la institución, en la comunidad.

En el polo opuesto, como bien lo distingue Bonifacio Barba, la sociedad moderna presenta características particulares. Los primeros rasgos son la racionalidad y el cambio, y como los orígenes de la sociedad son humanos y conocidos, a mayor uso de la razón más posibilidad de avanzar. En este sentido, la sociedad moderna y las instituciones educativas modernas, tienen que ver con el uso del tiempo y la magnificación de las capacidades humanas, en el marco de una competencia en busca de lo mejor. El localismo es a la sociedad tradicional, lo que el cosmopolitismo - la idea de mundo global, diríamos ahora- a la sociedad moderna, la cual tiene que ver con el comercio extensivo, la amplitud física de las comunicaciones, la producción económica, la innovación tecnológica y la exploración científica y el mejoramiento significativo de los sistemas educativos a fin de preparar a los individuos modernos.
¿Y cuál es el "individuo moderno" que se quiere formar? Si las instituciones de educación superior surgen con los procesos de modernización socioeconómica, ¿cómo se espera que salgan los egresados? Y si no salen con una personalidad moderna, ¿cuáles son las causas por las cuales la función modernizadora de la educación superior no se cumple? Según dos teóricos de la modernización, Inkeles y Smith, la personalidad moderna se caracteriza por la autonomía y la iniciativa individual. Además, se trata de un ciudadano que participa y es autónomo, que está abierto a nuevas experiencias e ideas, se identifica con lo nuevo, se interesa por asuntos públicos (locales, nacionales e internacionales) y rechaza la pasividad, la resignación y el fatalismo.

Con estos rasgos sobre lo tradicional y lo moderno se puede interpretar aún más el origen y desarrollo de las instituciones de educación superior en Aguascalientes. Y el libro abre las puertas a nuevas investigaciones sobre los últimos cambios que tendieron a responder a la reforma modernizadora de Carlos Salinas de Gortari. Por cierto, en el libro no queda clara la delimitación entre lo moderno y lo neoliberal del salinismo. Uno se pregunta: ¿cuándo se es moderno y cuándo neoliberal? ¿En qué se distinguen y cuáles son los rasgos comunes? 
Siguiendo esta misma línea de interpretación, se podrían hace más preguntas a los mismos datos que el mismo autor aporta cuando describe muy bien las historias de las instituciones. Por ejemplo: ¿la postura religiosa y al mismo tiempo proempresarial de la Universidad Bonaterra es moderna o tradicional? El énfasis que se puso a la reforma de los institutos tecnológicos y que afectó al Tecnológico de Aguascalientes en 1992, ¿es un rasgo de modernización o de neoliberalismo?. Lo mismo puede preguntarse del impulso que el gobierno del estado le dio a la Universidad Tecnológica de Aguascalientes, al grado de querer crear otra para el año 2004. Las resistencias al cambio en el Instituto Tecnológico Agropecuario y sus vínculos con la familia Olivares Ventura, ahora derotada políticamente, ¿pueden considerarse como rasgos de un mundo tradicional que se opone a la modernización y a la "postura tecnócrata del neoliberalismo"?.

Es pertinente detenerse en el caso de la UAA, de la cual el autor fue autoridad durante el periodo 1996-1998. ¿Cómo podemos leer, como investigadores educativos y no sólo como miembros de esta institución, el Proyecto de Modificaciones a la Ley Orgánica de la UAA, de 1996, cuando en este mismo proyecto se decía textualmente que la Universidad había perdido "dinamismo" y que en los noventa, mien- tras otras instituciones de educación superior emprendían reformas para enfrentar los desafíos del entorno, la UAA no lo hacía?. El documento, específicamente, resumía las debilidades de la Universidad en cinco puntos: falta de iniciativa y liderazgo; desánimo y pasividad; falta de vínculos con la sociedad; estructuras rígidas que no alentaban la investigación, el posgrado y la extensión, y estructuras que no facilitaban la toma de decisiones.

Frente a este reconocimiento, frente a este mundo de rasgos tradicionales, digámoslo así, se comenzó a poner en marcha el proyecto de reforma que fue aplaudido por los miembros de la ANUIES, pero que paradójicamente provocó resistencias al interior de la institución. ¿En el caso de la UAA, hoy por hoy, qué estamos presenciando? ¿Cómo hacer un análisis objetivo, una interpretación seria y profesional, con las herramientas teóricas y metodológicas de la investigación educativa, de esta realidad socio-institucional que nos aleje de juicios simples y visiones coyunturales? Lo importante, creo, es retomar esta preocupación académica que el excelente libro de Bonifacio Barba Casillas nos sugiere, para profundizar en el análisis y el debate.

En suma, la actualidad y pertinencia del libro es muy grande: puede ser leído no sólo por los estudiosos de la educación de Aguascalientes, sino también por las 
autoridades responsables de la educación, | perspectivas para las discusiones que de los tecnológicos y las universidades, mantienen quienes toman decisiones en así como por los maestros y estudiantes del la Secretaría de Educación Pública y en nivel superior. Incluso, este trabajo abre la ANuIEs. 